The nuclease sensitivity of active genes

Robert H.Nicolas ${ }^{+}$, Carol A.Wright ${ }^{+}$, Peter N.Cockerill ${ }^{+}$, John A.Wyke* and Graham H.Goodwin ${ }^{+}$

+ Department of Cell and Molecular Biology, Institute of Cancer Research, Fulham Road, London SW3 6JB, and *Imperial Cancer Research Fund Laboratories, P.O. Box 123, Lincoln's Inn Fields, London WC2A 3PX, UK

Received 5 November 1982; Revised and Accepted 5 January 1983

\begin{abstract}
Brief micrococcal nuclease digestion of chick embryonic red blood cells results in preferential excision and solubilization of monomer nucleosomes associated with $\beta-g l o b i n$ sequences and also $5^{\prime}$-sequences flanking the $B-g l o b i n$ gene. Both regions are DNAse-I sensitive in nuclei. Such salt-soluble nucleosomes are enriched in all four major HMG proteins but HMGl and 2 are only weakly associated. These nucleosomes appear to have lost much of the DNAse-I sensitivity of active genes. The HMGl4 and 17-containing salt-soluble nucleosomes separated by electrophoresis are not DNAse-I sensitive and contain inactive gene sequences as well as active sequences. Reconstitution of HMG proteins onto bulk nucleosomes or chromatin failed to reveal an HMG-dependent sensitivity of active genes as assayed by dot-blot hybridization and it was found that the DNAse-I sensitivity of ASV proviral sequences as assayed by dot-blot hybridization was not HMG-dependent. These results indicate that higher order chromatin structures might be responsible for nuclease sensitivity of active genes.
\end{abstract}

\title{
INTRODUCTION
}

It is known that the chromatin structure of transcriptionally active genes in eukaryotes differs from bulk transcriptionally inactive chromatin in that active genes are more susceptible to digestion by nucleases. In the case of DNAse-I, active gene sequences are digested to non-hybridizing fragments more rapidly than inactive sequences and evidence has been presented that nucleosomes associated with active genes are rendered more susceptible to digestion by the binding of the two chromosomal proteins HMGl4 and $17(1,2)$. In the case of micrococcal nuclease, monomer nucleosomes associated with active genes are preferentially excised from the chromatin and it has been supposed that this preferential excision is a consequence of the genes being actively transcribed by RNA polymerase molecules $(3,4)$. Examination of the proteins associated with the nucleosomes rapidly solubilized from nuclei by digestion with micrococcal nuclease in the presence of divalent metal ions (5) show that they are enriched in the HMG proteins HMGl4 and 17 (and a related protein HMGY) and that they lack histone Hl $(6,7)$. Similarly, monomer nucleosomes soluble in $0.1 \mathrm{M} \mathrm{NaCl}$ are 
enriched in transcribed sequences and enriched in HMG proteins $(8,9)$. Such results are consistent with the notion that HMGl4 and 17 proteins are specifically associated with active genes. Nucleosomes solubilized in the above procedures can be fractionated by electrophoresis into principally two types of particle: core particles of 145 base pairs of DNA and particles with longer length DNA (150-160 bp) which lack Hl but have 1-2 molecules of HMGl4,17 (6). The increased length of DNA in the latter suggested that the HMG proteins might interact with the DNA at the ends of the chromatosome, i.e. in the region where the globular section of histone $\mathrm{Hl}$ binds. In this study we have investigated the nuclease sensitivity of active genes by the dot-blot hybridization method and we found that brief micrococcal nuclease digestion of nuclei from chick erythrocytes results in the preferential excision and solubilization of monomer nucleosomes containing adult $\beta$-globin sequences into the salt-soluble 1SF fraction (5). Surprisingly sequences 5'-flanking the $\beta$-globin gene were also highly enriched in this salt-soluble nucleosome fraction. These sequences are also DNAse Isensitive. However, the HMG-containing nucleosomes solubilized into such fractions were no more DNAse I-sensitive than salt-soluble nucleosomes lacking HMG proteins. Also comparison of active and inactive gene sequences in these two types of nucleosomes revealed no preferential distribution of active sequences in the HMG-containing nucleosomes. Moreover, removing HMG proteins from chromatin or nucleosomes and reconstituting with HMG proteins did not affect DNAse Isensitivity of active genes as assayed by dot-blot hybridization.

MATERIALS AND METHODS

1. Preparation of $\mathrm{ISF}$ and $\mathrm{Mg}$-soluble monomer nucleosomes from chicken embryonic red blood cells (see Fig.1)

All buffers except digestion buffer contained $0.5 \mathrm{mM}$ PMSF. Nuclei were prepared from red blood cells from 14-16 day chick embryos by washing with RSB buffer (10 mM NaCl, $10 \mathrm{mM}$ Tris- $\mathrm{HCl}, \mathrm{pH} 7.5,3 \mathrm{mM} \mathrm{MgCl} 2$ ) (1). Nuclei were suspended in RSB buffer containing $1 \mathrm{mM} \mathrm{CaCl} 2$ at $5 \mathrm{mg} / \mathrm{ml}$ DNA and digested with 200 units/ml micrococcal nuclease for $2 \mathrm{~min}$ at $370 \mathrm{C}$ ( $1.5-28$ acid-soluble nucleotides). The nuclei were pelleted, and the supernatant made $5 \mathrm{mM}$ EDTA and $0.5 \mathrm{mM}$ PMSF. This supernatant fraction is termed 1SF following Bloom \& Anderson (5). The pelleted nuclei were lysed in $2 \mathrm{mM}$ EDTA pH 8 at a DNA concentration of $10 \mathrm{mg} / \mathrm{ml}$ and the suspension centrifuged $(16,000 \mathrm{~g}, 30 \mathrm{~min})$. An equal volume of $12 \mathrm{mM} \mathrm{MgCl} 2$ $100 \mathrm{mM} \mathrm{NaCl}, 20 \mathrm{mM}$ Tris-HCl pH 7.5, $2 \mathrm{mM} \mathrm{EGTA}$, was added to the supernatant and the precipitate that formed centrifuged down $(70,000 \mathrm{~g}, 30 \mathrm{~min})$. The resulting supernatant (Mg-soluble fraction) was collected. About 18 of the total DNA is solubilized as monomer nucleosomes in the Mg-soluble and ISF fractions. DNA was isolated from the two supernatant fractions as described below.

2. Isolation of DNA and protein from red blood cell ISF nucleosomes separated by polyacrylamide gel electrophoresis

Nuclei suspended in $50 \mathrm{mM}$ Tris $-\mathrm{HCl}, \mathrm{pH} 7.5,1 \mathrm{mM} \mathrm{CaCl}{ }_{2}$ were digested with micrococcal nuclease ( 4.58 acid-soluble nucleotides). The monomer nucleosomes 
in the 1SF supernatant were purified by Biogel chromatography in buffer containing $40 \mathrm{mM} \mathrm{NaCl}$ and separated electrophoretically in a slab polyacrylamide gel containing $50 \mathrm{mM} \mathrm{NaCl}$ (7). Two bands SMl and SM2 (detected by ethidium bromide staining) were cut out and the gel crushed and extracted three times with 18 SDS, TEA-EDTA buffer, dialysed versus the same buffer and extracted three times with phenol. Protein was precipitated from the phenol phase with HCl and 6 volumes of acetone (6). The aqueous phase containing DNA was dialysed versus $0.15 \mathrm{M} \mathrm{NaCl}, 50 \mathrm{mM}$ Tris-HCl, $1 \mathrm{mM}$ EDTA, $\mathrm{pH} 8$ and loaded onto a small DEAE-cellulose column. The DNA was eluted with $1.5 \mathrm{M} \mathrm{NaCl}, 50 \mathrm{mM}$ Tris-HCl, $1 \mathrm{mM}$ EDTA, $\mathrm{pH} 8$, dialysed versus $0.4 \mathrm{M}$ sodium acetate $\mathrm{pH} 6$ and precipitated with ethanol.

3. DNAse I digestion of salt-soluble and HMG-reconstituted nucleosomes

Chick embryonic red blood cell nuclei were digested with micrococcal nuclease (28 acid-soluble nucleotides), and resuspended in $0.1 \mathrm{M} \mathrm{NaCl}, 10 \mathrm{mM}$ TEA-2 mM EDTA, pH 7.6 (see Fig. 1). The suspension was centrifuged and the supernatant dialysed versus $10 \mathrm{mM} \mathrm{NaCl}, 10 \mathrm{mM}$ Tris-HCl, pH 7.6, $0.2 \mathrm{mM}$ EGTA. The nucleosomes in the supernatant were digested with DNAse I (128 acidsoluble nucleotides) after adding $3 \mathrm{mM} \mathrm{MgCl}_{2}$. Digestion was terminated by adding EDTA and SDS and the DNA was isolated and checked for the $10 \mathrm{bp}$ ladder on a denaturing gel.

For the reconstitution experiment 'stripped' bulk monomer nucleosomes were prepared from a micrococcal nuclease digestion ( 38 acid-soluble nucleotides) by centrifugation through a 5-208 sucrose gradient containing $0.6 \mathrm{M}$ $\mathrm{NaCl}, 2 \mathrm{mM}$ EDTA, $10 \mathrm{mM}$ Tris-HCl, $\mathrm{pH} 7.5$. The stripped monomer nucleosomes were dialysed versus $0.4 \mathrm{M} \mathrm{NaCl}, 0.2 \mathrm{mM}$ EGTA, $5 \mathrm{mM}$ sodium phosphate buffer, $\mathrm{pH}$ 7.2. The monomers were divided into three portions and reconstituted with different amounts of purified chicken HMG17. The three solutions were dialysed

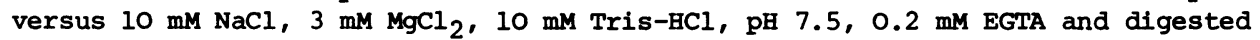
with DNAse I as above. After addition of EDTA and SDS, DNA was isolated from the digests as described below and checked that the $10 \mathrm{bp}$ cutting patterns were comparable.

4. DNAse I digestion of avian sarcoma virus-transformed rat cells (VIT)

Nuclei were prepared by washing with RSB as for red blood cells. The nuclei were divided into two portions, one of which was washed twice with RSB and the other twice with $0.34 \mathrm{M} \mathrm{NaCl}, 10 \mathrm{mM}$ Tris- $\mathrm{BCl}, \mathrm{pH} 7.4,3 \mathrm{mM} \mathrm{MgCl} 2$. Both portions were then washed twice with RSB. For DNAse I digestion of intact nuclei, the nuclei were resuspended to $0.5 \mathrm{mg} / \mathrm{ml}$ DNA in RSB, and digested with $8-20 \mu \mathrm{g} / \mathrm{ml}$ of DNAse I, until 18-208 of the DNA was rendered acid soluble. For the preparation of chromatin, salt-extracted and unextracted nuclei were resuspended at $1.5 \mathrm{mg} / \mathrm{ml}$ DNA in RSB, $1 \mathrm{mM} \mathrm{CaCl} 2$, and digested briefly with 15 units/ml micrococcal nuclease for 1 min at $37^{\circ} \mathrm{C}$. The digested nuclei were diluted with 3 volumes of RSB, $1 \mathrm{mM}$ EGTA, centrifuged for $10 \mathrm{~min}$ at $750 \mathrm{~g}$ at $4{ }^{\circ} \mathrm{C}$, and lysed by gentle homogenization in $10 \mathrm{mM}$ EDTA, $0.5 \mathrm{mM}$ PMSF, $\mathrm{pH} 7.5$, and dialysed against $0.5 \mathrm{mM}$ EDTA, $0.5 \mathrm{mM}$ PMSF, $\mathrm{pH} 7.4$ overnight at $4^{\circ} \mathrm{C}$. The portion of nonsalt-extracted chromatin was dialysed into RSB, and the portion previously extracted with $0.34 \mathrm{M} \mathrm{NaCl}$ was divided into two portions, one of which was dialysed into RSB, and the other reconstituted with HMG proteins. The reconstitution was performed by addition of $2 \mathrm{M} \mathrm{NaCl}$ and $1 \mathrm{M}$ Tris, $\mathrm{pH} 7.5$ to $0.33 \mathrm{M} \mathrm{NaCl}$, $10 \mathrm{mM} T r i s$, addition of total calf HMG proteins to give $1: 10 \mathrm{w} / \mathrm{w}$ protein:DNA and dialysis against RSB, all at $4^{\circ} \mathrm{C}$. Protein analysis showed that exogenous HMG bound to the chromatin but no check was made that SM2 nucleosomes were reconstituted. Chromatin samples were digested with DNAse I until 12-18\% of the DNA was rendered acid soluble. DNA was isolated and checked that the 10 bp ladders were the same. 


\section{Isolation of DNA}

Samples (generally in EDTA and dissociated with SDS) were extracted with phenol, then with chloroform-isoamyl alcohol, and precipitated with ethanol. RNA was removed by alkali treatment $\left(0.3 \mathrm{M} \mathrm{NaOH}, 65^{\circ} \mathrm{C} 30 \mathrm{~min}\right)$ and then neutralised with acetic acid. DNA concentrations were determined by their UV spectra.

\section{Dot-blot hybridization}

DNA samples $(3-5 \mathrm{mg} / \mathrm{ml}$ in $25 \mathrm{mM}$ sodium phosphate buffer, $\mathrm{pH} 5.5$, denatured at $100^{\circ} \mathrm{C}$ for $5 \mathrm{~min}$ ) were dotted on to diazoaminophenylthioester paper (DPT paper) (11). Prehybridization and hybridization in 508 formamide $41^{\circ}$ was carried out using the method described by wahl et al (12) except that the hybridization solutions did not contain $50 \mathrm{~mm}$ sodium phosphate. After hybridization with nick-translated $32 \mathrm{p}$-labelled probes $\left(1-2 \times 10^{8} \mathrm{cpm} / \mu \mathrm{g}\right)(24-48 \mathrm{~h})$ the paper was washed a total of eight times for up to $4 \mathrm{~h}$, in different concentrations of SSC buffer ( $1 \times$ SSC buffer is $0.15 \mathrm{M} \mathrm{NaCl}$ and 0.015 trisodium citrate). The washing solutions and temperatures were as follows: $2 \times$ SSC, 0.18 SDS, $25^{\circ} \mathrm{C} ; 2 \times \mathrm{SSC}, 0.18 \mathrm{SDS}, 65^{\circ} \mathrm{C} ; 0.1 \times \mathrm{SSC}, 0.18 \mathrm{SDS}, 65^{\circ} \mathrm{C}$ and $2 \times 0.18$ SDS, $25^{\circ} \mathrm{C}$. Autoradiography was carried out using preflashed Fuji RX film and Dupont intensifying screens at $-70^{\circ} \mathrm{C}$ for up to 2 weeks. Dot-blots that were hybridized with a second probe were first washed at $65^{\circ} \mathrm{C}$ for $30 \mathrm{~min}$ in $0.3 \mathrm{M}$ $\mathrm{NaOH}$ followed by distilled water under the same conditions followed by several washes with $25 \mathrm{mM}$ sodium phosphate buffer pH 5.5 at $25^{\circ} \mathrm{C}$. Quantitative analysis of dot-blots was carried out by scanning with a densitometer. Experiments were carried out to establish that the method is quantitative in the range of DNA loadings used in this paper $(2-20 \mu \mathrm{g})$. In some experiments nitrocellulose was used for dot-blot hybridization (13).

The following probes were used for dot-blot hybridization:(i) plasmid pHBlOOl containing a cDNA copy of the avian adult $\beta$-globin gene (14). (ii) pBR322 containing the avian ovalbumin tha.ov fragment of PCR.ov 2.1 (15). (iii) The $1 \mathrm{~Kb}$ EcoRI-SmaI fragment immediately flanking the avian adult $\beta$-globin gene on the $5^{\prime}-$ side, prepared by digesting plasmid PB 1BR15 (16) (which contains the ECORI-Bam Hl adult $\beta$-globin region) with EcORI and then SmaI (see map in 17). (iv) A plasmid pSRA2 containing cloned Rous avian sarcoma viral DNA (ASV) (18). (v) A plasmid pAl3 containing CDNA of a rat prostate androgen-sensitive gene (19).

\section{RESULTS}

1. Micrococcal nuclease sensitivity of $\beta$-globin expressed and $5^{\prime}$-flanking

\section{sequences}

Bloom and Anderson have demonstrated that brief digestion of oviduct nuclei with micrococcal nuclease followed by centrifugation results in the preferential solubilization of nucleosomes associated with the ovalbumin gene into the supernatant (the 1SF fraction) ie, such nucleosomes are soluble in buffer containing divalent metal ions (5). Using similar procedures (Fig.1) we find that nucleosomes associated with the $\beta$-globin gene in chick red blood cells are also preferentially soluble in solutions containing divalent metal ions (the ISF and Mgsoluble fraction, Fig.1). In this experiment nuclei were digested briefly (1-28 acid-soluble nucleotides) with micrococcal nuclease, centrifuged and the supernatant (ISF) containing monomer nucleosomes and subnucleosomes collected. The pellet was resolubilized in EDTA, and $\mathrm{Mg}^{2+}$ added to reprecipitate polynucleosomes 


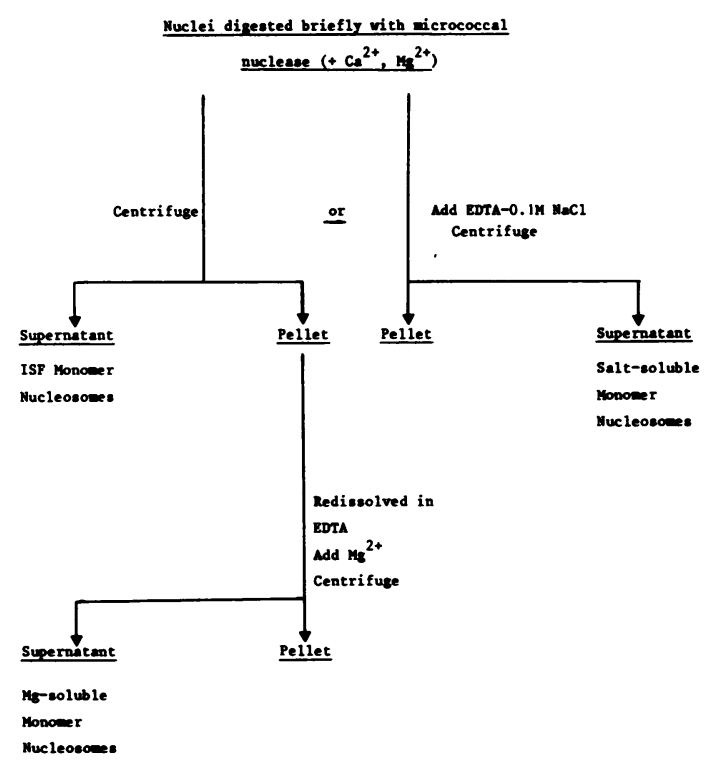

Fig. I Summary schematic diagram of the procedures to isolate salt-soluble monomer nucleosomes.

amd Hl-containing nucleosomes. After centrifugation the supernatant (Mg-soluble fraction) was collected. DNA was isolated from the two supernatant fractions and analysed for globin and ovalbumin sequences by dot-blot hybridization (Fig. 2a). It can be seen that compared with total unfractionated sonicated chicken DNA, DNA from the 1SF fraction and the Mg-soluble fraction are both enriched in the adult $\beta$-globin sequences and depleted in ovalbumin sequences. Scanning the spots of several such experiments showed that the Mg-soluble fraction was on average 2.5-fold enriched in $\beta$-globin sequences (range 1.6-3.2) and the 1SF fraction 3.2-fold (range 1.9-4.3). Surprisingly, when the same 1SF DNA samples were analysed by hybridization to a flanking sequence probe, $1 \mathrm{~Kb}$ immediately 5 'flanking to the adult $\beta$-globin gene (Fig.2b) we found much higher enrichments in the ISF fraction (6.4-fold; range 5.3-8.6). Analysis of the proteins associated with these monomer nucleosomes was carried out by purifying the monomer nucleosomes in the 1SF and Mg-soluble fractions on 5-20\% sucrose gradients containing $40 \mathrm{mM}$ Tris-acetate, $2 \mathrm{mM}$ EDTA, $\mathrm{pH}$ 8. The proteins isolated from the monomer peaks are shown in Fig.3a, and are compared semiquantitatively with total unfractionated chick erythrocyte nuclear protein. As we have shown previously with oviduct and thymus $(6,7)$ such nucleosomes are devoid of $\mathrm{Hl}$ and enriched in HMGl4 and 17 


\section{Nucleic Acids Research}

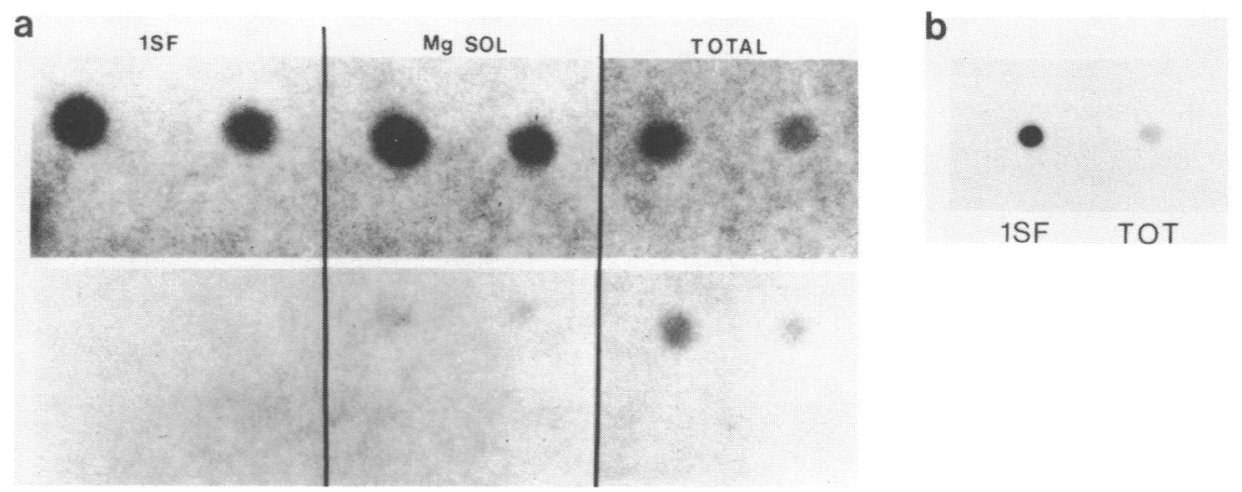

Fig. 2 Dot-blot hybridization analysis of salt-soluble nucleosomes of embryonic red blood cells.

(a) 5 and $10 \mu \mathrm{g}$ DNA from $1 \mathrm{SF}$ and Mg-soluble monomers and 5 and $10 \mu \mathrm{g}$ of total sheared chicken DNA were spotted in duplicate onto two sheets of DPT-paper; one was hybridized to B-globin probe (pHBlOOl) (upper row of spots) and the other to ovalbumin probe (lower row).

(b) $3.6 \mu \mathrm{g}$ 1SF DNA and $6.7 \mu \mathrm{g}$ total chicken DNA (TOT) hybridized to EcoRI-SmaI $\beta$-globin flanking probe.

(approximately 5-8 fold). Unlike the previous experiments with oviduct, which have very little HMGl and 2, the chick red blood cell salt-soluble monomers are very enriched in HMGl and 2. However, the binding of HMGl and 2 to such nucleosomes is weak since most of these two proteins can be removed by passing saltsoluble nucleosomes down gel-filtration columns in 50-100 mM NaCl (see below). It is possible that at lower ionic strengths the salt-soluble nucleosomes have picked up HMGl and 2 from the nucleoplasm during the digestion and so their presence in the nucleosomes of Fig. 3 may be artifactual.

The above results show that monomer nucleosomes associated with active genes preferentially fractionate into the ISF and Mg-soluble fractions. This may be due to the more exposed structure of active genes or due to the preferential solubility of nucleosomes bound to active genes (see Discussion). The enrichment of HMGl4 and 17 seen in these nucleosomes is consiștent with the idea that they are specifically associated with expressed sequences. Nucleosomes enriched in HMG proteins can also be prepared by selective solubilization in $0.1 \mathrm{M} \mathrm{NaCl}(6$, $8,9)$; such nucleosomes prepared as outlined in Fig.l are usually not so enriched in transcribed sequences as 1SF nucleosomes (about 2.5-fold in $\beta$-globin sequences, data not shown). It should be stressed that enrichments in the various salt-soluble fractions is dependent on the extent of digestion - the shorter the digestion the higher the enrichment. 

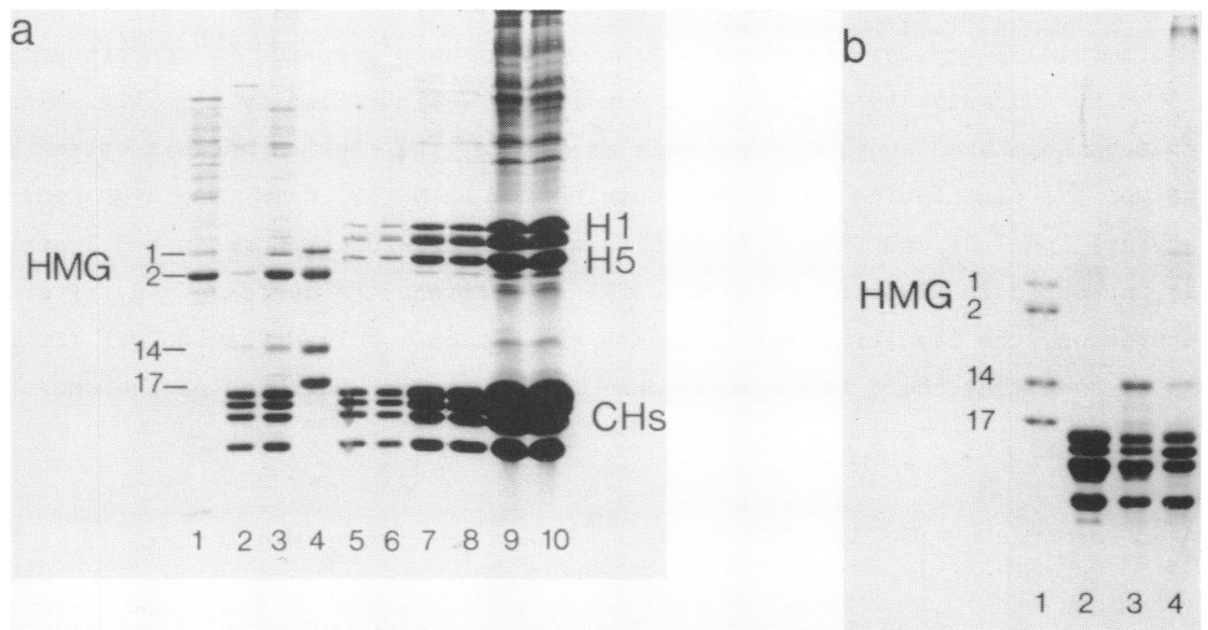

Fig. 3 Protein analysis of salt-soluble nucleosomes prepared from red blood cells.

(a) ISF and Mg-soluble fractions were prepared as outlined in Fig.l and then fractionated on a sucrose gradient. Protein was phenol extracted from the monomer nucleosome fractions and from the top of the gradient of the 1SF fraction. Protein from the unfractionated nucleus was also extracted for analysis on SDS - 158 polyacrylamide gels: Lane 1 - Protein at top of 1SF gradient; Lane 2 - ISF monomer protein; Lane 3 - Mg-soluble monomer protein; Lane 4 - a standard mixture of HMG proteins; Lanes 5,6 - $5 \mu$ g total nuclear protein; Lanes 7,8 - 25 $\mu \mathrm{g}$ total nuclear protein; Lanes, 9,10 - $100 \mu \mathrm{g}$ total nuclear protein. CHs stands for core histones.

(b) ISF monomer nucleosomes were electrophoretically separated into SMI and SM2, and the proteins isolated and analysed on an SDS-15\% polyacrylamide gel.

Lane 1 - standard HMG protein; Lane 2 - SMl proteins; Lane 3 - SM2 proteins; Lane 4 - proteins from gel filtration purified 1SF monomer nucleosomes.

\section{Properties of the HMG-containing salt-soluble nucleosomes}

Nucleosomes released into the $1 \mathrm{SF}$ fraction or by selective solubilization with $0.1 \mathrm{M} \mathrm{NaCl}$ are composed principally of two types of particle, core particles (SMI) and particles containing the four core histones plus 1-2 molecules of HMGl4 and 17 (and HMGY in oviduct) (SM2) (7). These nucleosomes can be fractionated by polyacrylamide gel electrophoresis and the HMG-containing nucleosomes isolated. We have investigated the DNAse I-sensitivity of the HMG-containing nucleosomes by electrophoretically separating ISF nucleosomes in a polyacrylamide gel containing DNAse I as described by Todd \& Garrard (10) and then reactivating the enzyme with divalent metal ions and analysing the DNA frag- 


\section{Nucleic Acids Research}

ments produced. The results of a typical experiment are shown in Fig.4. In this experiment ISF monomer nucleosomes from oviduct were prepared in the presence of a $5 \mathrm{mM}$ sodium butyrate as described previously (7), purified by gel filtration and then separated by electrophoresis as before, the electrophoresis buffer (in the gel and circulating solution) contained $40 \mathrm{mM} \mathrm{NaCl}, 10 \mathrm{mM} T E A, 5 \mathrm{mM}$ sodium butyrate ( $\mathrm{pH}$ 7.6) and DNAse I (25 units/ml). After electrophoresis a gel strip was incubated in RSB buffer (10 $\mathrm{min}, 370$ ) to activate the nuclease and, after denaturation, the resulting DNA fragments run out on a polyacrylamide gel (10). It can be seen that there is no difference in the cutting patterns of the HMG-

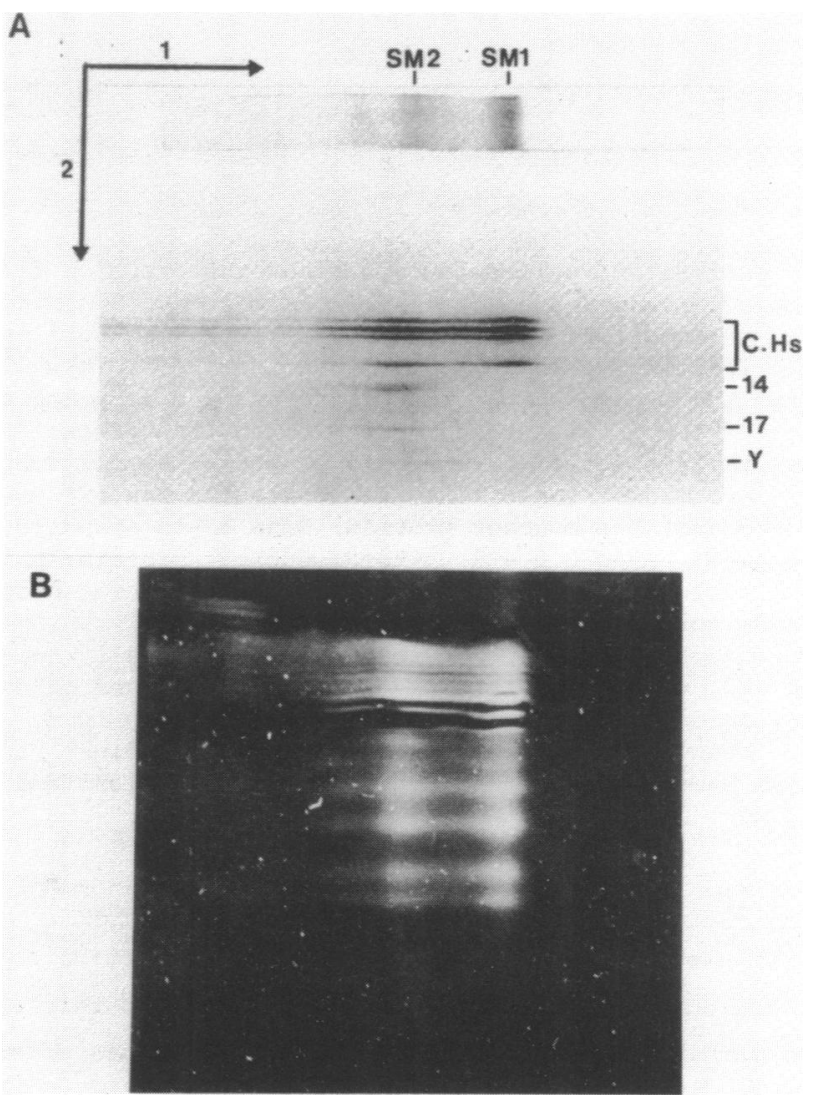

Fig. 4 DNAse I sensitivity of oviduct HMG-containing nucleosomes.

ISF nucleosomes were purified and separated on a slab gel containing DNAse I. A strip was analysed for protein on an acid urea gel (A) and another incubated with RSB and the DNA fragments analysed on a denaturing gel (B). 
containing particles (SM2) and the faster moving particle devoid of HMG proteins (SMl). The same result was obtained with $0.1 \mathrm{M} \mathrm{NaCl}$ soluble nucleosomes from chicken erythrocytes (data not shown).

In a second experiment ISF monomers from chick red blood cells were analysed for the presence of active and inactive sequences in the HMG-containing nucleosomes. In this experiment as in the preceding experiment we have avoided exposing the nucleosomes to very low ionic strengths in case this causes unfolding of the nucleosomes with consequent rearrangement of HMG proteins. Also higher ionic strengths should inhibit non-specific interactions between HMG proteins and nucleosomes. Thus after nuclease digestion monomer nucleosomes were purified and fractionated at $\sim 50 \mathrm{mM}$ ionic strength. 16-day chick embryonic red blood cells were digested with micrococcal nuclease in $50 \mathrm{mM}$ Tris- $\mathrm{HCl}, 1 \mathrm{mM}$ $\mathrm{CaCl}_{2}$, centrifuged and the monomer nucleosomes in the 1SF supernatant purified by gel filtration as described previously (7). The monomers were then fractionated by polyacrylamide gel electrophoresis, the electrophoresis buffer containing $50 \mathrm{mM} \mathrm{NaCl}$. DNA and protein were extracted from the two bands. A protein gel (Fig.3b) confirms that the SMl band is core particle and SM2 band is the HMGl4/ 17 -containing nucleosome (which is also devoid of histone $\mathrm{Hl}$ ) and is enriched 20 fold in HMGl4. (Note the absence of HMGI and 2). Dot-blot analysis of the DNA from the two bands is shown in Fig. 5. It can be seen that the SM2 band has both ovalbumin and $\beta$-globin sequences, ie, the HMG containing nucleosomes are not derived solely from active genes. In this experiment the nuclease digestion was

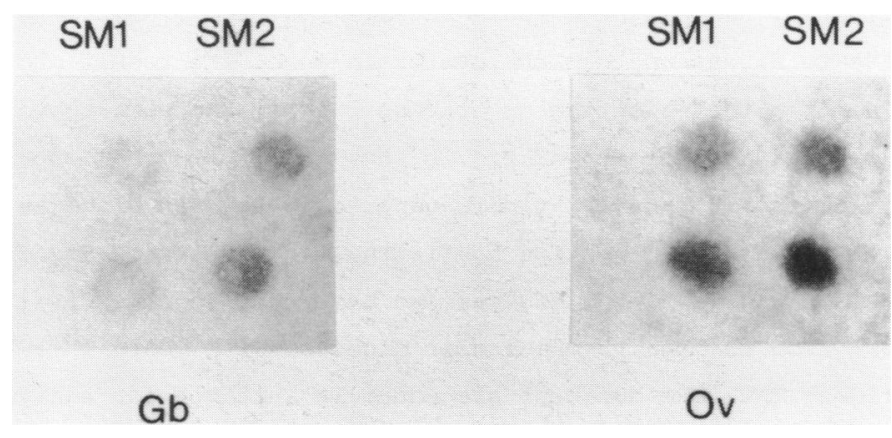

Fig. 5 Dot-blot hybridization analysis of red blood cell SMl and SM2 DNA. Two sheets of DPT-paper were loaded with DNA from SMI and SM2 nucleosomes electrophoretically prepared from red blood cell ISF fraction. One sheet was probed with B-globin pHBlOOl (Gb) and the other with ovalbumin probe (ov). Two loadings of each sample were spotted onto each sheet: SMl -4.5 and $9.0 \mu \mathrm{g}$; SM2 -2.7 and $5.4 \mu \mathrm{g}$. 
more extensive (4.5\% acid-soluble nucleotides) than the preceding experiments. Also the specific activity of the ovalbumin probe is twice that of the globin probe and these factors explain the higher signal of ovalbumin sequences in Fig. 5 as compared with Fig.2a.

The results of the above experiments indicate that although HMG-containing nucleosomes are preferentially excised from nuclei together with active and flanking sequences in short nuclease digestions (1-28 acid-soluble nucleotides), when purified by gel electrophoresis the HMG-containing nucleosomes in saltsoluble nucleosome fractions do not have the expected properties of being specifically associated with DNAse I-sensitive active genes.

\section{DNAse I-sensitivity of $\beta$-globin genes}

In view of our inability to detect a DNAse I sensitivity of the HMG-containing nucleosomes in the oviduct $1 \mathrm{SF}$ fraction it was decided to investigate the DNAse I-sensitivity of specific genes more closely and we chose to use the dot-blot procedure again for this investigation. To make sure that this procedure is suitable for analysing DNAse I-sensitivity several experiments were carried out to check the methodology. Chicken erythrocyte nuclei were digested with DNAse I until 98 of the DNA was rendered acid-soluble. The DNA was isolated and analysed by dot-blot hybridization using $\beta$-globin, $\beta$-globin flanking and ovalbumin probes. Fig.6a shows that with the $\beta$-globin probe the level of hybridization of the DNAse I digested DNA is very much reduced in comparison with total undigested chicken DNA (sheared to about 500 bp by sonication). When the same samples are analysed with the ovalbumin probe the level of hybridization is hardly affected. Scanning the spots reveals that the globin gene is 10 times more sensitive to digestion than the ovalbumin gene. The result shown in Fig. $6 a$ was obtained from dot-blotting on nitrocellulose; the same result was obtained with DPT-paper (data not shown).Fig.6b shows that using DPT-paper sequences immediately flanking the adult $\beta$-globin gene in 16 day red blood cells are also very sensitive to DNAse I digestion confirming the results of stalder et al. (21) and Wood \& Felsenfeld (24). In this case we have compared the level of hybridization to DNA from chicken thymus nuclei digested with DNAse I (178 acid-soluble nucleotides). Thus the dot-blot procedure is suitable for analysing the DNase I sensitivity of active genes and it shows that flanking sequences as well as expressed sequences are equally DNAse I-sensitive.The pHBlOOl probe is specific for the 'adult' $\beta$-globin genes using our hybridization and washing conditions since a Southern blot (22) of BamHl restricted chicken DNA run on an agarose gel gave two bands (data not shown), one at about $4 \mathrm{~Kb}$ which contains the adult $\beta-$ globin gene and a fainter $2 \mathrm{~Kb}$ fragment which contains the 'hatching' $\beta^{\mathrm{H}}$-globin, 

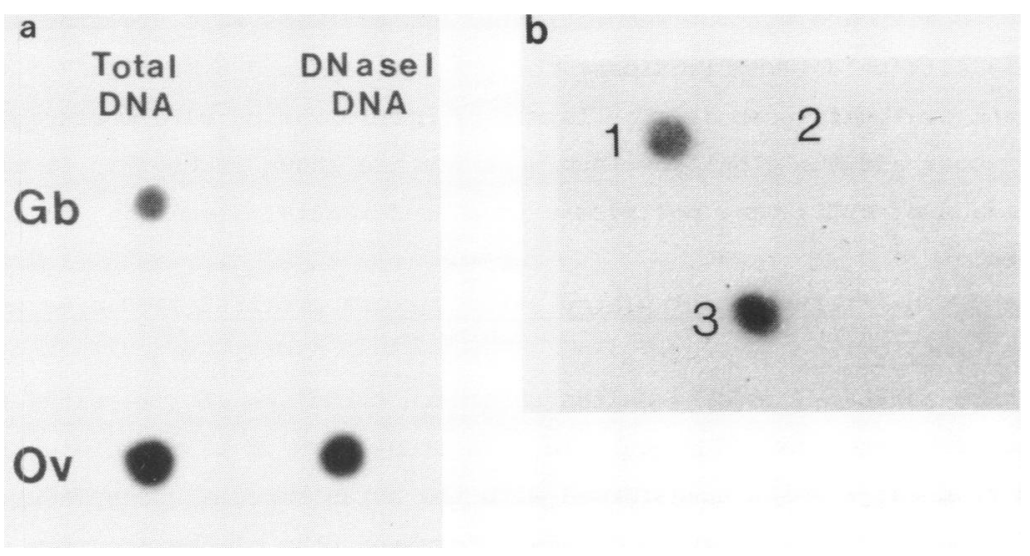

Fig. 6 DNAse I sensitivity of B-globin and flanking sequences in red blood cell nuclei.

(a) DNA from DNAse I digested erythrocyte nuclei and total (sheared) DNA were spotted in duplicate onto two sheets of nitrocellulose paper and probed with $\beta$-globin (top two samples) and ovalbumin (bottom two samples). The DNAse I digested sample probed with B-globin (top right) gave only a faint spot and this has been lost in the photographic reproduction.

(b) The same two samples as above $(6.7 \mu \mathrm{g})$ were spotted onto DPTpaper together with DNA $(5 \mu \mathrm{g})$ from DNAse I digested chicken thymus nuclei. The paper was hybridized with the 1Kb EcoRI-SmaI fragment flanking the adult $\beta$-globin gene. 1 - DNAse I digested thymus nuclei; 2 - DNAse I digested RBC nuclei; 3 - total chicken DNA.

both of which are expressed in the red blood cells of adult lineage (21).

Monomer nucleosomes soluble in $0.1 \mathrm{M} \mathrm{NaCl}$ were isolated from 16-day red blood cells and digested with DNAse I (128 acid-soluble nucleotides). The levels of hybridization of $\beta-g l o b i n$ and ovalbumin gene probes to the DNA from undigested and DNAse I digested salt-soluble nuclesomes were measured by scanning the spots of autoradiographs of dot-blot hybridizations. A globin/ovalbumin ratio of 0.46 was obtained for undigested monomer and a ratio of 0.36 for the DNAse I digested sample. This small drop ( $\sim 20 \%$ ) in the globin sequences (relative to ovalbumin) after DNAse I digestion of monomers is very much less than the 10-fold reduction observed with intact nuclei. Thus salt-soluble monomers appear to have lost much of their DNAse I sensitivity of active sequences, at least when assayed by the dot-blot hybridization method.

We have also carried out reconstitution experiments in which bulk monomer nucleosomes were prepared, stripped of their HMG proteins and H1/H5 histones by salt extraction, then reconstituted with varying amounts of HMGl7. The 
nucleosomes with and without reconstituted BMG proteins were digested with DNAse I (10-15\% acid-soluble nucleotides) the DNA isolated and hybridized to the $\beta-$ globin and ovalbumin probes. The levels of hybridization were measured by scanning the spots and the globin/ovalbumin ratios are shown in Fig.7. It can be that the addition of HMGl7 does not result in a preferential digestion of globin gene sequences.

4. DNAse I sensitivity of integrated avian sarcoma proviral sequences in transformed cells

We have initiated studies on the chromatin structure of integrated retroviral genes in transformed cells. In this study we have used a clone of cells derived from Rat-1 cells transformed with the avian sarcoma virus (ASV). These cells (termed VIT cells) have a single integrated copy of the provirus and this has previously been shown to be in a DNAse I sensitive conformation (23). An examination of the HMG proteins in these cells show that they are qualitatively very similar to the proteins extracted from normal rat cells - the four main HMG proteins are all present. The only difference we have seen is that the transformed cells have a higher HMGl4/HMG17 ratio than either the original Rat-1 cells or transformed cells that have reverted to the normal phenotype without losing the proviral sequences (data not shown). Whether this high HMGl4/ 17 ratio is a common feature of all cells expressing high levels of src gene is currently being investigated. In order to investigate whether HMG proteins have any effect on the chromatin structure of the proviral genes, nuclei were prep-

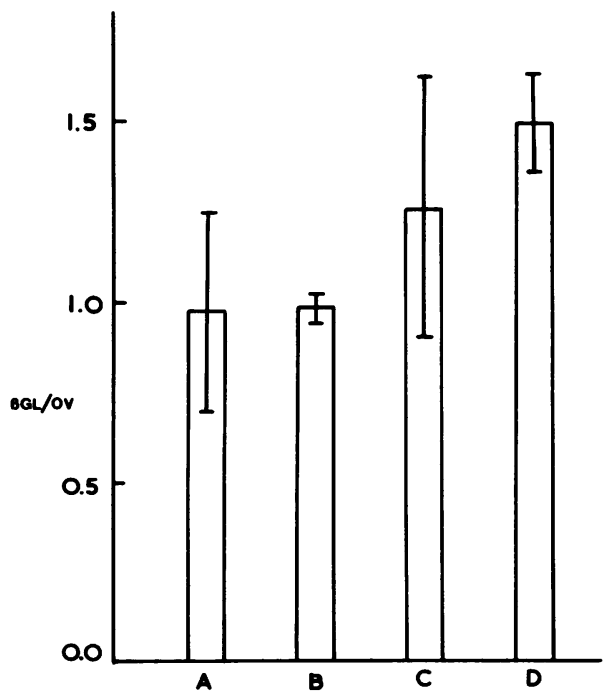

Fig. 7 DNAse I sensitivity of HMGreconstituted monomer nucleosomes from red blood cells. DNA from salt-stripped monomers (A), from DNAse I digested salt-stripped monomers (B), and from DNAse I digested monomers reconstituted with 1 mol HMGl7 per 10 nucleosomes (C), or 1 mol HMGl 7 per 3 nucleosomes (D), were each loaded onto two sheets of DPT-paper and hybridized to $\beta$-globin (pHB1001) and ovalbumin probes respectively. The histogram shows the ratio of globin to ovalbumin sequences in each sample. 
ared, divided into two portions and one half was extracted twice with $0.34 \mathrm{M}$ $\mathrm{NaCl}$ to remove HMG proteins. (The HMG proteins are quantitatively removed with two salt washes since electrophoretic analysis of PCA-extracts of the washed nuclei reveal no HMG proteins - data not shown). Chromatin was prepared from the extracted and unextracted nuclei by brief nicking with micrococcal nuclease and lysis with EDTA. The chromatin suspensions were then digested with DNAse I (12-18\%) and the DNA isolated. Also for comparison, VIT DNA from undigested nuclei was extracted and digested with DNAse I to approximately the same size as the other samples. The samples were then analysed by dot-blot hybridization using a plasmid containing the ASV proviral sequences. As a control for non-expressed sequences the samples were hybridized to a plasmid containing a gene not expressed in Rat-1 cells, the Al3 gene, an androgensensitive gene expressed in prostate tissue (19). The results are shown in Fig. 8. It can be seen that the Al3 gene is not DNAse I sensitive since the level of hybridization of the DNA from DNAse I digested nuclei is not reduced relative to that of VIT DNA from undigested nuclei, and this result is unaffected by $0.34 \mathrm{M} \mathrm{NaCl}$ extraction. The ASV sequences are reduced in the chromatin DNAse I digested samples compared with VIT DNA. From scanning the spots it was calculated that the level of hybridization drops by about 3-fold (Table 1). This DNAse I sensitivity is not significantly affected by removal or readdition of the HMG proteins. The same result was obtained from similar experiments in which nuclei instead of chromatin were digested; that is, rem-

(a)

$$
\text { NATIVE -HMG +HMG }
$$$$
\begin{array}{llllll}
5 & 10 & 5 & 10 & 5 & 10
\end{array}
$$

ASV (b)

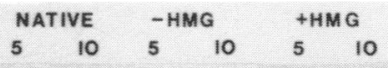

A 13
2 TOTAL DNA
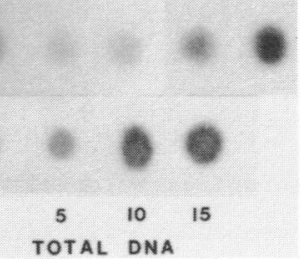
$2 \begin{array}{ccc}5 & 10 & 15 \\ \text { TOTAL DNA } & \end{array}$

Fig. 8 DNAse I sensitivity of ASV sequences in VIT transformed cells. DNA from DNAse I digested chromatin (native), from DNAse I digested salt-extracted chromatin (-HMG) and from DNAse I digested saltextracted chromatin reconstituted with HMGl, 2, 14 and 17 (+HMG) was spotted onto two sheets of DPT-paper. In addition pure DNA isolated from VIT cells was reduced to comparable size to the above samples by brief DNAse I digestion and several loadings $(2-25 \mu \mathrm{g})$ applied to the papers. Numbers on the figure refer to loadings of DNA in $\mu \mathrm{g}$. The two sheets of paper were analysed for ASV and Al3 sequences as described in Table 1. 
Table 1 DNAse I sensitivity of ASV sequences in VIT rat transformed cells

\begin{tabular}{|lc|}
\hline Sample & ASV sequences \\
\hline & A13 sequences \\
\hline VIT DNA & 1.00 \\
DNA from VIT chromatin digested & 0.35 \\
with DNAse I & 0.34 \\
$\begin{array}{l}\text { DNA from VIT-salt-extracted chromatin } \\
\text { digested with DNAse I }\end{array}$ \\
$\begin{array}{l}\text { DNA from VIT salt-extracted chromatin } \\
\text { reconstituted with HMG and digested } \\
\text { with DNAse I }\end{array}$
\end{tabular}

Samples were spotted in duplicate on two sheets of DPT paper and hybridized to ASV or Al3 probes. The levels of hybridization to the two probes were measured by scanning the spots on the autoradiograph. The probes were removed from the DPT paper by alkali and the two sheets reprobed but switching over the probes. The spots were scanned again and the mean ratio of ASV sequences to Al3 sequences determined; the figures are normalised so that the ratio for VIT DNA is 1.00 .

oval of HMG protein had little effect on the level of hybridization of the ASV sequences of DNAse I digested nuclei (data not shown). These results were confirmed using Southern blots to analyse the disappearance of ASV restriction fragments with increasing DNAse I digestion; ASV sequences disappeared faster than (inactive) albumin sequences and this was not affected by the presence or absence of HMG proteins (data not shown).

\section{DISCUSSION}

In this paper we have shown that brief micrococcal nuclease digestion of embryonic erythrocytes results in the preferential solubilization of nucleosomes associated with $\beta-g l o b i n$ gene sequences and 5'-flanking sequences into the salt-soluble nucleosomal fractions; $i . e$. these nucleosomes are soluble in buffers of intermediate ionic strength (20-50 mM) containing divalent metal ions or in $0.1 \mathrm{M} \mathrm{NaCl-EDTA.} \mathrm{(Whilst} \mathrm{this} \mathrm{manuscript} \mathrm{was} \mathrm{in} \mathrm{preparation,} \mathrm{Wood}$ \& Felsenfeld (24) published a paper showing micrococcal sensitivity of $\beta-$ globin flanking sequences also). Since the inactive ovalbumin gene sequences are depleted (especially in the ISF fraction) (Fig.2) one could reasonably generalise the results to other genes and suggest that all active red blood cell genes are preferentially solubilized into the salt-soluble nucleosome fractions. 
We also confirm that $\beta$-globin $5^{\prime}$-flanking sequences as well as the $\beta$-globin sequences are sensitive to DNAse I digestion but in the rather limited studies we have carried out we do not see any difference in the sensitivity of the two types of sequences. The preferential solubilization of nucleosomes bound to active and flanking sequences following brief micrococcal digestion could be due to a difference in the higher order folding of active (and flanking) chromatin domains as compared with inactive chromatin. A more exposed nucleosomal linker DNA would result in the preferential excision of active monomer nucleosomes resulting in the dissociation of histone $\mathrm{Hl}$ and the consequent solubilization of these nucleosomes. Several other studies have shown enrichment of active gene sequences in monomer nucleosome preparations $(3,4,5,8,9)$ and it has been suggested that this micrococcal sensitivity is a consequence of the genes being actively transcribed by RNA polymerase molecules $(3,4)$. The fact that the upstream 5'- $\beta$-globin sequences are apparently more micrococcal sensitive than the downstream expressed sequences is of interest in connection with results showing that in chicken erythrocytes, although the $\beta$-globin gene is transcribed at a very low level, engaged RNA polymerase molecules can be detected at the 5'end of the gene (42). Also very recently in vitro RNA transcripts from sequences immediately upstream of the $\beta$-globin gene have been detected in chick red blood cell nuclei, albeit at a lower level than transcripts from the $\beta$-globin gene itself (46).

Salt-soluble Hl-depleted nucleosomes are enriched in HMGl4 and 17 proteins (Fig.3), as has been reported previously $(6,7,8,9)$. This enrichment is consistent with the postulate that the HMGl4/17 proteins are specifically associated with active gene sequences, evidence for this having come from previous nuclease digestion experiments and from the finding that transcriptionally active nucleosomes bind preferentially to HMGl4 and 17 (25). Following Weintraub and Groudine's original discovery that transcriptionally active sequences are complexed with nuclear proteins in a DNAse I sensitive conformation in the cell nucleus (1), it has now become well established that most if not all genes that are transcriptionally active are in this DNAse I sensitive configuration; 10-20\% of the genome is transcribed in most cells and this is mostly DNAse I sensitive. Evidence has been presented by Weisbrod, Groudine and Weintraub that DNAse I sensitivity is due to the binding of HMG14/17 to nucleosomes bound to active sequences (25). From estimates of the quantities of HMGl4 and 17 proteins in the cell nucleus it can be calculated that, if there is one HMGbinding site per active nucleosome, then there is just sufficient HMG protein to complex with 10-20z of the total number of nucleosomes in the cell nucleus 
(26). Thus, numerically, there is sufficient HMG protein to account for the DNAse I sensitive structure of all the transcriptionally 'competent' nucleosomes in the cell nucleus if most of the HMGl4/17 in the nucleus is associated with these nucleosomes. However, analysis of the HMG-containing nucleosomes in the 1SF fraction does not support the view that HMG proteins are solely associated with active nucleosomes. After purification by polyacrylamide electrophoresis the HMG-containing nucleosomes were found not to be particularly DNAse I sensitive even though the separation of HMG-containing nucleosomes had been carried out in the presence of sodium butyrate (to prevent loss of histone acetyl groups which may be important for HMG binding) and at $50 \mathrm{mM}$ ionic strength to inhibit non-specific binding of HMG proteins (Fig.4). Also, the HMG-containing nucleosomes from chick red blood cells purified by electrophoresis were not noticeably depleted in inactive (ovalbumin) gene sequences (Fig.5). This latter result is compatible with our previous finding that HMGcontaining nucleosomes from chicken erythrocytes prepared by solubilization into $0.1 \mathrm{M} \mathrm{NaCl}$ and gel electrophoresis were no more than 2-fold enriched in $\alpha$ and $\beta-g l o b i n$ sequences (20). It is of interest to note that sandeen et al (28) found that reconstituted HMG-containing nucleosomes were only about 2fold enriched in $\beta$-globin gene sequences. These results, together with our finding that salt-soluble nucleosomes have lost most of the DNAse I sensitivity of the globin gene, suggest that either the HMG proteins are not solely associated with active nucleosomes in the cell nucleus or that protein rearrangement can occur during micrococcal nuclease digestion.

It is useful at this stage of the discussion to consider some observations recently published by other laboratories. Although Weintraub and coworkers have demonstrated quite clearly that monomer nucleosomes retain DNAse I sensitivity of active genes, Garel and Axel were unable to show DNAse I sensitivity of the ovalbumin gene in oviduct monomer nucleosomes (29). A more recent detailed analysis by Senear and Palmiter (30) showed that isolated core particles have lost the DNAse I sensitivity of the ovalbumin gene. Monomer nucleosomes and polynucleosomes from less extensive micrococcal digests at $0^{\circ} \mathrm{C}$ lost about half the DNAse I sensitivity of the ovalbumin gene and the sensitivity that remained was about the same as we find for globin sequences in salt-soluble nucleosomes (i.e. 208 reduction in the active/inactive gene ratio after DNAse I digestion). Also the sensitivity that remained was only marginally affected by prior extraction with $0.6 \mathrm{M} \mathrm{NaCl}$ (which removed HMG proteins and histone $\mathrm{Hl})$. Levinger et al $(31,32)$, separating monomer nucleosomes by electrophoresis, have found that HMGl4 and 17-containing nucleosomes are 
not particularly enriched in transcribing sequences nor depleted in satellite sequences; Rendelhuber et al (33) in fact found an enrichment of satellite sequences in HMG-containing nucleosomes. Mathew et al (34) found HMGl4 and 17 in isolated satellite chromatin, though depleted in quantity (a more recent analysis suggests that satellite chromatin contains no HMG protein (45)). Several other studies of chromatin fractions substantially enriched in transcribed sequences have not found elevated quantities of HMGl4 and $17(35,36)$. On the other hand, Albanese and Weintraub (37) reported that electrophoretically purified chicken erythrocyte monomers with mobilities slower than core particles containing globin sequences, were depleted in (but not devoid of) ovalbumin sequences and contained HMGl4/17 protein but no Hl. However, from the protein analysis of these particles it seemed possible that not all these nucleosomes had HMG protein associated with them.

The only way in which we can reconcile the conflicting data on this topic is to suppose that protein rearrangement can occur under some conditions when nuclei are fragmented with nucleases; the fact that most of the nucleosomes in the cell nucleus have the capacity to bind HMGl4/17 proteins makes this very likely $(28,43,44)$. It is possible, for example, that HMGl4 and 17 proteins rearrange during nuclease digestion because of the movement of histone $\mathrm{Hl}$. We have shown previously that when salt-soluble nucleosomes are fractionated by polyacrylamide gel electrophoresis the DNA of the HMG-containing particles is 150-160 bp whilst the faster moving core particles have shorter DNA ( 146 bp) (6). This suggested that the HMGI4 and 17 proteins partially bind into the $\mathrm{Hl}$-binding region of the chromatosome at the two ends of the DNA. Put in another way, it is possible that HMGl 4 and 17 prefer to bind to particles with more free DNA. Thus we could envisage that during micrococcal nuclease digestions there is dissociation of $\mathrm{Hl}$ from active and inactive monomer nucleosomes which results in free double- (or possibly single-) stranded DNA becoming available for HKG-binding and this results in HMGl4 and 17 migrating from specific sites in active nucleosomes to sites originally occupied by $\mathrm{Hl}$ on active and inactive nucleosomes in the salt-soluble nucleosome fraction.

If the HMG proteins do rearrange in this way during micrococcal nuclease digestions then this could also explain the loss of most of the DNAse I sensitivity of globin sequences in salt-soluble nucleosomes and ovalbumin sequences in oviduct monomer nucleosomes (30). This could explain why in the reconstitution experiments with bulk salt-stripped monomer nucleosomes we could not reconstitute a DNAse I sensitive conformation by adding HMG17 though one has to be careful not to generalise since we did not try reconstitution with HMGl4 also. 
Although rearrangement artifacts could explain the loss of most of the DNAse I sensitivity of active genes in isolated monomer nucleosomes, it is more difficult to use this explanation for our inability to detect any substantial differences in the DNAse I sensitivity of proviral sequences in transformed cells before and after $0.34 \mathrm{M} \mathrm{NaCl}$ extraction. The result was obtained with nuclei as well as with the very briefly digested chromatin. Again, in seeking an explanation for this enigma, the paper by Senear and Palmiter (30) is apposite. Extraction of oviduct nuclei with salt solutions ( $0.4 \mathrm{M}$ and above) was shown to remove about half the DNAse I sensitivity of the ovalbumin gene. This suggested that DNAse I sensitivity might be due to more than one chromosomal factor - a salt-extractable factor (not necessarily HMG protein since $0.3-0.35 \mathrm{M} \mathrm{NaCl}$ extraction had little effect on DNAse I sensiitivity) and some other feature of nucleosomes or chromatin. It is of interest to note that the difference in the DNAse I sensitivity of the ovalbumin gene before and after $0.4 \mathrm{M} \mathrm{NaCl}$ extraction was only about 1.5-fold, as assayed by solution hybridization. If the ASV sequences in the rat transformed cells resemble the ovalbumin gene in oviduct in this respect it may not have been possible to detect such a small change in the sensitivity of the ASV sequences before and after $0.35 \mathrm{M}$ $\mathrm{NaCl}$ extraction using the dot-blot hybridization method. The fact that DNAse I sensitivity is mostly lost when monomer nucleosomes are isolated might therefore suggest that higher order chromatin structures are at least in part responsible for the DNAse I sensitivity of active genes. This view is supported by the micrococcal nuclease digestion experiments which could be interpreted as reflecting a difference in the higher order structure of active genes (see above). Also, DNAse I sensitivity is not confined to expressed sequences only since a number of studies have shown that extensive regions surrounding active genes are also DNAse I sensitive $(21,24,47)$. It is unlikely that this could all be due to HMG-binding in view of the limited quantity of HMGl 4 and 17 in the cell nucleus and again suggests that some other structural feature of chromatin is responsible.

\section{Acknowledgements}

We would like to thank S.Weisbrod and G.Felsenfeld for useful discussions. We would also like to thank S.Weisbrod,D.Engel, W.Salser, P.Chambon, M.Bellard and M.Parker for supplying and allowing us to use the various cloned probes used in this study. Our thanks to Mrs. Sian Searle for growing the VIT cells and to Drs. A.Hall and D.Chiswell for advice on nucleic acid techniques. This work was supported by a grant from the MRC to E.W. Johns. 


\section{References}

1. Weintraub, H. and Groudine, M. (1976) Science 193, 848-856.

2. Weisbrod, S., Groudine, M. and Weintraub, H. (1980) Cell 19, 289-301.

3. Bellard, M., Gannon, F. and Chambon, P. (1977) Cold Spring Harbor Symp. Quant.Biol. 42, 779-793.

4. Bloom, K.S. and Anderson, J.N. (1979) J.Biol.Chem. 254, 10532-10539.

5. Bloom, K.S. and Anderson, J.N. (1978) Cell 15, 141-150.

6. Goodwin, G.H., Mathew, C.G.P., Wright, C.A.W., Venkov, C. and Johns, E.W. (1979) Nucleic Acids Res. 7, 1815-1835.

7. Goodwin, G.H., Wright, C.A. and Johns, E.W. (1981) Nucleic Acids Res. 9, 2761-2775.

8. Levy, W.R., Connor, W. and Dixon, G.H. (1979) J.Biol.Chem. 254, 609-620.

9. Egan, P.A. and Levy-Wilson, B. (1981) Biochemistry 20, 3695-3702.

10. Todd, R.D. and Garrard, W.T. (1977) J.Biol.Chem. 252, 4729.

11. Seed, B. (1982) Nucleic Acids Res. 10, 1799-1810.

12. Wahl, G.M., Stern, M. and Stark, G.R. (1979) Proc.Natl.Acad.Sci. 76, 3683-3687.

13. Thomas, P.S. (1980) Proc.Natl.Acad.Sci. 77, 5201-5205.

14. Salser, W.A., Cummings, I., Liu, A., Strommer, J., Padayatty, J. and Clarke, P. (1979) in Cellular and Molecular Regulations of Haemoglobin Switching, Stamatoyannopoulos, G. and Nienhuis, E. Eds., pp. 621-643, Grune and Stratton.

15. Humphries, P., Cochet, M., Krust, A., Gerlinger, P., Kornisky, P. and Chambon, P. (1977) Nucleic Acids Res. 7, 2389-2405.

16. Dolan, M., Sugarman, B.J., Dodgson, J.B. and Engel, J.D. (1981) Cell 24, $669-677$.

17. Wood, W.I., Nickol, J. and Felsenfeld, G. (1981) J.Biol.Chem. 256, $1502-1505$.

18. Delorb, W.J., Luciw, P.A., Goodman, H.M., Varmus, H.E. and Bishop, J.M. (1980) J.Virology 36, 50-61.

19. Parker, M., Needham, M. and White, R. (1982) Nature 298, 92-94.

20. Mathew, C.G.P., Goodwin, G.H., Wright, C.A. and Johns, E.W. (1981) Cell Biology Int.Rep. 5, 37-43.

21. Stalder, J., Larsen, A., Engel, J.D., Dolan, M., Groudine, M. and Weintraub, H. (1980) Cell 20, 451-460.

22. Southern, E.M. (1975) J.Mol.Biol. 98, 503-517.

23. Chiswell, D.J., Gillespie, D.A. and Wyke, J.A. (1982) Nucleic Acids Res. 10, 3907-3979.

24. Wood, W.I. and Felsenfeld, G. (1982) J.Biol.Chem. 257, 7730-7736.

25. Weisbrod, S. (1982) Nature 297, 289-295.

26. Goodwin, G.H. and Mathew, C.G.P. (1982) in The HMG Chromosomal Proteins, Johns, E.W. Ed., pp. 193-221, Academic Press.

27. Weisbrod, S. and Weintraub, H. (1981) Cell 23, 391-400.

28. Sandeen, G., Wood, W.I. and Felsenfeld, G. (1980) Nucleic Acids Res. 8, 3757-3778.

29. Garel, A. and Axel, R. (1976) Proc.Natl.Acad.Sci. 73, 3960-3971.

30. Senear, A.W. and Palmiter, R.D. (1981) J.Biol.Chem. 256, 1191-1198.

31. Levinger, L., Barsoum, J. and Varshavsky, A. (1981) J.Mol.Biol. 146,287-304.

32. Barsoum, J., Levinger, L. and Varshavsky, A. (1982) J.Biol.Chem. 257, 5274-5282.

33. Rendelhuber, T.L., Ball, D.J., Davis, A.H. and Garrard, W.T. (1982) Nucleic Acids Res. 10, 1311-1325.

34. Mathew, C.G.P., Goodwin, G.H., Igo-Kemenes, T. and Johns, E.W. (1981) FEBS Lett. 125, 25-29.

35. Gabrielli, F., Hancock, R. and Faber, A.J. (1981) Eur.J.Biochem. 120, 363-369. 
36. Goldsmith, M.E. (1981) Nucleic Acids Res. 9, 6471-6485.

37. Albanese, I. and Weintraub, H. (1980) Nucleic Acids Res. 8, 2787-2805

38. Reference deleted.

39. McGhee, J.D., Wood, W., Dolan, M., Engel, J.D. and Felsenfeld, G. (1981) Cel1 27, 45-55.

40. Larsen, A. and Weintraub, H. (1982) Cell 29, 609-622.

41. Weintraub, H., Larsen, A. and Groudine, M. (1981) Cell 24, 333-344.

42. Gariglio, P., Bellard, M. and Chambon, P. (1981) Nucleic Acids Res. 9. 2589-2628.

43. Albright, S.C., Wiseman, J.M., Lange, K.A. and Garrard, W.T. (1980) J.Biol.Chem. 255, 3677-3684.

44. Mardian, J.K.W., Paton, A.E., Burnick, G.J. and Olins, D.E. (1980) Science 209, 1534-1536.

45. Zhang, X.Y. and Horz, W. (1982) Nucleic Acids Res. 10, 1481-1494.

46. Villeponteux, B., Landes, M.G., Pankratz, M.J. and Martinson, H.G. (1982) J.Biol.Chem. 257, 11015-11023.

47. Lawson, G.M., Knoll, B.J., March, C.J., Woo, S.L.C., Tsai, M.-J. and O'Malley, B.W. (1982) J.Biol.Chem. 257, 1501-1507. 